Letter

\section{Critical paediatric COVID-19: varied presentations but good outcomes}

International reports of the COVID-19 pandemic have described the relative sparing of children, both in case frequency ${ }^{1}$ and disease severity. ${ }^{2-4}$ The major presentation described in children is the paediatric inflammatory multisystem syndrome temporally associated with SARS-CoV-2 (PIMS-TS) - many of these children do not have evidence of PCRpositive viral disease and therefore may represent a postinfectious phenomenon. ${ }^{5}$ We describe our single-centre paediatric intensive care unit (PICU) experience of children who tested positive for severe acute respiratory syndrome coronavirus 2 (SARS-CoV-2) in the first 10 weeks of the pandemic in the UK, excluding those who met PIMS-TS criteria as these have been described elsewhere.

A total of 313 children were admitted to our intensive care units (ICUs) from the 26 March 2020 to the 31 May 2020. Ninety-six children were suspected to have COVID-19 of which 24 (25\%) children tested reverse transcription (RT-PCR) positive at admission with SARS-CoV-2 on nasopharyngeal aspirate. Thirteen children presented with a PIMS-TS phenotype; here, we describe the characteristics and course of the remaining 11.

The demographic and presenting characteristics are shown in table 1. Comorbidities were present in nine out of eleven children. Four (36\%) children were from a black, Asian or minority ethnic background. The clinical characteristics are presented in table 2. Inflammatory markers were raised, but the range of maximum values during admission were widely variable.

Four children had respiratory disease fulfilling the 2015 PALICC (the paediatric acute lung injury consensus conference) criteria for paediatric acute respiratory distress syndrome. Hypoxaemic respiratory failure management included prone ventilation $(n=4)$ and inhaled pulmonary vasodilators $(\mathrm{n}=3)$. Two infants were escalated to high frequency oscillation due to refractory hypoxia on conventional ventilation. Median duration of ventilation was 13 days (IQR 10-15.5 days).

The remaining seven children required admission to PICU for reasons other

Table 1 Presentation characteristics of children presenting to PICU with a PCR-positive diagnosis of SARS-CoV-2 infection. Children who presented with a paediatric inflammatory multisystem syndrome were excluded from this description

\begin{tabular}{|c|c|}
\hline Characteristics & Patients $(n=11)$ \\
\hline Median age, years (IQR) & $5(0.4-11.1)$ \\
\hline Male, $\mathrm{n}(\%)$ & $9(81)$ \\
\hline Ethnicity: Black, Asian and minority ethnic, $n(\%)$ & $4(36)$ \\
\hline \multicolumn{2}{|l|}{ PIM3 predicted mortality, n (\%) } \\
\hline$<1 \%$ & $5(42)$ \\
\hline $1 \%-5 \%$ & $4(36)$ \\
\hline $5 \%-15 \%$ & $1(9)$ \\
\hline $15 \%-30 \%$ & 0 \\
\hline$>30 \%$ & $1(9)$ \\
\hline \multicolumn{2}{|l|}{ Coexisting disorder, $\mathrm{n}(\%)$} \\
\hline Weight above 91 st centile & $3(27)$ \\
\hline Cancer & $1(9)$ \\
\hline Pre-existing respiratory disease* & $2(18)$ \\
\hline Prematurity & $2(18)$ \\
\hline Congenital heart disease & $1(9)$ \\
\hline Median duration of symptoms before admission, no of days (IQR) & $2(1.5-3)$ \\
\hline \multicolumn{2}{|l|}{ Primary presenting symptoms, $\mathrm{n}(\%)$} \\
\hline Cough & $6(55)$ \\
\hline Apnoea & $3(27)$ \\
\hline Fever & $10(90)$ \\
\hline Gastrointestinal (abdominal pain/vomiting/diarrhoea) & $6(55)$ \\
\hline Seizurest & $3(27)$ \\
\hline \multicolumn{2}{|l|}{ Microbiology } \\
\hline SARS-CoV-2 RT-PCR positive on nasopharyngeal aspirate & $11(100)$ \\
\hline RSV or influenza RT-PCR positive on nasopharyngeal aspirate & 0 \\
\hline Sputum cultures positive for other organisms & $2(10) \ddagger$ \\
\hline Blood culture positive for other organisms & 0 \\
\hline \multicolumn{2}{|l|}{ Chest radiography findings, $\mathrm{n}(\%)$} \\
\hline No new parenchymal changes & $3(64)$ \\
\hline Parenchymal changes including acute on chronic changes & $8(36)$ \\
\hline
\end{tabular}

*Pre-existing respiratory disorder included chronic lung disease and non-cystic fibrosis bronchiectasis. tTwo of the children presented had previously defined epilepsy.

¥Equivocal growth of Staphylococcus aureus and Candida albicans.

PICU, paediatric intensive care unit; PICU, paediatric intensive care unit; PIM3, paediatric index of mortality version 3; RSV, respiratory syncytial virus; RT-PCR, reverse transcription polymerase chain reaction; SARS-CoV-2, severe acute respiratory syndrome coronavirus 2 .

than respiratory failure. Three children presented in status epilepticus (two with known seizure disorders and one with an acquired head injury). All tested negative for SARS-CoV-2 on cerebrospinal fluid analysis. Three children presented with significant new diagnoses (congenital heart disease, leukaemia and diabetes mellitus) which would have required PICU admission regardless of their SARS-CoV-2 status. The other child was undergoing chemotherapy for a malignancy and was on established longterm ventilation but did not require a significant escalation in their ventilator parameters. Two of the cohort were immunocompromised.

Among other therapies, five (45\%) children received vasoactive drugs. None received renal replacement therapy or extracorporeal membrane oxygenation. Five children $(45 \%)$ received compassionate use of remdesivir following ethics review. Six children (55\%) received prophylactic anticoagulation as part of a modification of our usual practice. The two infants developed line-associated thrombosis in the absence of prophylaxis requiring therapeutic anticoagulation.

All children survived to discharge from PICU.

While children can present to PICU with a pattern of illness similar to adult COVID-19 disease, this is rare and three-quarters of them had risk factors for respiratory infections. A larger number of children were found to be SARS-CoV-2 positive coincidentally. While a causal relationship between some presentations and SARS-CoV-2 
Table 2 Summary of clinical characteristics and interventions for children with a PCR-positive diagnosis of SARS-CoV-2 infection. Children who presented with a paediatric inflammatory multisystem syndrome were excluded from this description

\begin{tabular}{|c|c|}
\hline Blood markers & Median measurement (range) \\
\hline Maximum leucocyte count $\left(\times 10^{9} / \mathrm{L}\right)$ & $15.4(6.01-24.75)$ \\
\hline Lymphocyte count $\left(\times 10^{9} / \mathrm{L}\right)$ & $1.15(0-2.94)$ \\
\hline Maximum ferritin ( $\mu \mathrm{g} / \mathrm{L})$ & $898(264-1991)$ \\
\hline Maximum LDH (units/L) & $1594(802-4264)$ \\
\hline Maximum D-dimer ( $\mu \mathrm{g} / \mathrm{L})$ & $1655(162-6742)$ \\
\hline Maximum CRP (mg/L) & $158(27-449)$ \\
\hline Maximum temperature during ICU admission $\left({ }^{\circ} \mathrm{C}\right)$, median (IQR) & $39.5(38.4-40)$ \\
\hline \multicolumn{2}{|l|}{ OSI, median (IQR) } \\
\hline Day 1 & $5.2(4.1-7.0)$ \\
\hline Day 2 & $6.6(4.3-7.6)$ \\
\hline Day 3 & $5.1(3.6-6.74)$ \\
\hline \multicolumn{2}{|l|}{ ICU therapies, $\mathrm{n}(\%)$} \\
\hline Invasive mechanical ventilation & $9(81)$ \\
\hline Prone position & $4(36)$ \\
\hline Neuromuscular blockade & $5(46)$ \\
\hline Inhaled pulmonary vasodilators* & $4(36)$ \\
\hline High-frequency oscillation ventilation & $2(11)$ \\
\hline Renal replacement therapy & 0 \\
\hline ECMO & 0 \\
\hline Vasoactive drugs & $5(46)$ \\
\hline \multicolumn{2}{|l|}{ Anticoagulation, $\mathrm{n}(\%)$} \\
\hline Therapeutic dose & $3(27)$ \\
\hline Prophylactic dose & $5(46)$ \\
\hline \multicolumn{2}{|l|}{ Antiviral medication, $\mathrm{n}(\%)$} \\
\hline Remdemisvir & $5(46)$ \\
\hline \multicolumn{2}{|l|}{ Outcomes } \\
\hline Survival to ICU discharge & 11 \\
\hline Survival to hospital discharge & 11 \\
\hline Median length of ICU stay (IQR), days & $10(3.2-13.0)$ \\
\hline
\end{tabular}

Entire ranges presented for maximum or minimum blood parameters rather than IQRs.

*Inhaled nitric oxide or inhaled prostacyclin.

tLeucocyte and lymphocyte counts include results from two children with oncological diagnoses.

$\ddagger$ OSI data exclude data from two children not ventilated and one child prior to correction of cyanotic congenital heart disease.

CRP, C reactive protein; ECMO, extracorporeal membrane oxygenation; ICU, intensive care unit; $L D H$, lactate dehydrogenase; OSI, oxygen saturation index; SARS-CoV-2, severe acute respiratory syndrome coronavirus 2.

infection cannot be ruled out, these cases will have implications for hospital infection control precautions in children with critical illness throughout the pandemic.

Nicholas Lanyon, ${ }^{1}$ Pascale du Pré, ${ }^{2}$

Timothy Thiruchelvam, ${ }^{3}$ Samiran Ray $\odot{ }^{2,4}$

Mae Johnson ${ }^{0},{ }^{2}$ Mark J Peters ${ }^{2,4}$

${ }^{1}$ Anaesthetic Department, Great Ormond Street Hospital For Children NHS Trust, London, UK

${ }_{2}^{2}$ Paediatric Intensive Care Unit, Great Ormond Street Hospital For Children NHS Foundation Trust, London, UK

${ }^{3}$ Cardiac Intensive Care, Great Ormond Street Hospital, London, United Kingdom
${ }^{4}$ Institute of Child Health, University College of London, London, UK

Correspondence to Dr Mae Johnson, Paediatric Intensive Care, Great Ormond Street Hospital for Children, London WC1N 3JH, UK; mae.johnson@gosh.nhs.uk

Twitter Samiran Ray @DrSamRay and Mark J Peters @pus27

Acknowledgements All research at Great Ormond Street Hospital NHS Foundation Trust and UCL Great Ormond Street Institute of Child Health is made possible by the National Institute for Health Research (NIHR) Great Ormond Street Hospital Biomedical Research Centre. We thank all the hospital and ICU staff members who cared for the children during the time of this pandemic.
Contributors NL and MJ: conceptualisation. NL: data curation. PdP, TT, SR and MJ: supported data interpretation. NL, PdP and MJ: wrote manuscript.

Funding The authors have not declared a specific grant for this research from any funding agency in the public, commercial or not-for-profit sectors.

Disclaimer The views expressed are those of the author(s) and not necessarily those of the National Health Service, the NIHR or the Department of Health.

Competing interests None declared.

Patient consent for publication Not required.

Provenance and peer review Not commissioned; internally peer reviewed.

This article is made freely available for use in accordance with BMJ's website terms and conditions for the duration of the covid-19 pandemic or until otherwise determined by BMJ. You may use, download and print the article for any lawful, non-commercial purpose (including text and data mining) provided that all copyright notices and trade marks are retained.

(c) Author(s) (or their employer(s)) 2021. No commercia re-use. See rights and permissions. Published by BMJ.

\section{A) Check for updates}

To cite Lanyon N, du Pré $\mathrm{P}$, Thiruchelvam T, et al. Arch Dis Child 2021;106:e10.

Accepted 15 June 2020

Published Online First 29 June 2020

Arch Dis Child 2021;106:e10

doi:10.1136/archdischild-2020-319602

\section{ORCID iDs}

Samiran Ray http://orcid.org/0000-0002-3738-4672 Mae Johnson http://orcid.org/0000-0003-1560-5689 Mark J Peters http://orcid.org/0000-0003-3653-4808

\section{REFERENCES}

1 International Severe Acute Respiratory and Emerging Infections Consortium (ISARIC). COVID-19 report. Available: https://media.tghn.org/medialibrary/2020/05/ ISARIC_Data_Platform_COVID-19_Report_19MAY20. pdf [Accessed 19 May 2020]

2 Castagnoli R, Votto M, Licari A, et al. Severe acute respiratory syndrome coronavirus 2 (SARSCoV-2) infection in children and adolescents: a systematic review. JAMA Pediatr 2020. doi:10.1001/ jamapediatrics.2020.1467. [Epub ahead of print: $22 \mathrm{Apr}$ 2020].

3 Parri N, Magistà AM, Marchetti F, et al. Characteristic of COVID-19 infection in pediatric patients: early findings from two Italian pediatric research networks. Eur J Pediatr 2020. doi:10.1007/s00431-020-03683-8. [Epub ahead of print: 03 Jun 2020].

4 Zachariah P, Johnson CL, Halabi KC, et al. Epidemiology, clinical features, and disease severity in patients with coronavirus disease 2019 (COVID-19) in a children's hospital in New York City, New York. JAMA Pediatr 2020:e202430

5 Toubiana J, Poirault C, Corsia A, et al. Kawasaki-like multisystem inflammatory syndrome in children during the covid-19 pandemic in Paris, France: prospective observational study. BMJ 2020;369:m2094. 